\title{
Lumbar Spondylolysis and Spondylolytic Spondylolisthesis: Who Should Be Have Surgery? An Algorithmic Approach
}

\author{
Farzad Omidi-Kashani ${ }^{1}$, Mohamad Hossein Ebrahimzadeh ${ }^{2}$, Saman Salari ${ }^{3}$ \\ ${ }^{I}$ Orthopedic Research Center, Orthopedic Department, Imam Reza Hospital, Mashhad University of Medical Sciences, Mashhad, Iran \\ ${ }^{2}$ Orthopedic Research Center, Ghaem Hospital, Mashhad University of Medical Sciences, Mashhad, Iran \\ ${ }^{3}$ Orthopedic Department, Imam Reza Hospital, Mashhad University of Medical Sciences, Mashhad, Iran
}

Lumbar spondylolysis and spondylolisthesis are common spinal disorders that most of the times are incidental findings or respond favorably to conservative treatment. In a small percentage of the patients, surgical intervention becomes necessary. Because too much attention has been paid to novel surgical techniques and new modern spinal implants, some of fundamental concepts have been forgotten. Identifying that small but important number of patients with lumbar spondylolysis or spondylolisthesis who would really benefit from lumbar surgery is one of those forgotten concepts. In this paper, we have developed an algorithmic approach to determine who is a good candidate for surgery due to lumbar spondylolysis or spondylolisthesis.

Keywords: Spondylolysis; Spondylolisthesis; Lumbosacral Region; Surgical Procedures.

\section{Introduction}

Currently in the treatment of lumbar spondylosis and spondylolisthesis, a lot of attention has been paid to new surgical techniques and implants used in minimally invasive spine surgeries, while basic science and concepts are frequently ignored. Numerous papers have proposed a variety of treatment modalities for lumbar spondylolysis and spondylolisthesis in numerous papers, while adequate attention is not being paid to the proper surgical indications.

First, it is necessary to differentiate a few similar terms related to spinal issues. These include spondylosis (osteoarthritis of the spine), spondylodesis (intervertebral fusion), spondylolysis (a defect in the pars interarticularis of the vertebra), spondylolisthesis (slipping of a vertebra on the vertebra below), and spondyloptosis (falling off or down of a vertebra that is completely dislocated). Spondylolysis and spondylolisthesis are two common spinal abnormalities that some authors regard as normal variants. In most cases, they are accidentally discovered during a work-up being done for another reason. What should we do? Do all the patients with vertebral slippage need surgery? Are they emergency cases? In this review, we tried to compile the latest information regarding the decision-making process for surgery in patients with lumbar spondylolysis and spondylolisthesis without any attention to the various surgical techniques used for their treatment.

Received Jun 16, 2014; Revised Jul 27, 2014; Accepted Aug 3, 2014

Corresponding author: Farzad Omidi-Kashani

Orthopedic Research Center, Orthopedic Department, Imam Reza Hospital, Imam Reza Square,

Mashhad University of Medical Sciences, Mashhad, Iran. Postal Code: 913791-3316.

Tel: +98-51-3854-3031, Fax: +98-51-3859-5023, E-mail: omidif@mums.ac.ir 


\section{Spondylolysis}

Spondylolysis is the most common cause of low back pain (LBP) in pediatric patients [1]. The child typically describes a history of activity-related pain, and $40 \%$ recall a specific traumatic event [2]. The reported prevalence of spondylolysis is $6 \%-11.5 \%$ and in $15 \%$ of the patients, particularly in females, it can progress to spondylolisthesis $[3,4]$. Progression to a slipped vertebra is not usually associated with pain. This abnormality mostly occurs during a growth spurt, with minimal change after the age of 16 [5-7]. Spondylolysis is more common in first-degree relatives and white (versus black) patients with a male to female ratio of about $2-3$ to $1[8,9]$.

\section{Diagnosis}

For proper treatment, it's necessary to be able to recognize it in time. In a child who presents with refractory or atypical LBP suggestive of spondylolysis, lumbosacral Xrays are indicated. Bilateral defects are easily recognized on a lateral radiograph but unilateral lesions are usually better detected on an oblique view (Fig. 1), although recent studies have questioned the value of these oblique films [10]. Lateral lumbosacral views should always be taken in standing posture to assess any associated spondylolisthesis and spinopelvic parameters that are essential in making therapeutic decisions. As lumbar hyperlordosis is a predisposing factor for developing spondylolysis, standing full-length radiographs of the spine are neces- sary to rule out associated thoracic hyperkyphosis, including Scheuerman's kyphosis.

All spondylotic defects cannot be detected on plain radiographs, especially in patients with normal lumbar radiographs. But persistent pain or disability is suggestive of the disease and single photon emission computed tomography may be the most valuable and sensitive method of identifying spondylolysis [11,12]. Other imaging modalities that can be used to better visualization of integrity and status of the posterior vertebral elements may include a computed tomography (CT) scan, bone scan, or magnetic resonance imaging (MRI) [13-16]. A technetium bone scan is very helpful in the diagnosis of spondylolysis and during treatment. Increased radioisotope uptake is indicative of the presence of osseous activity and healing potential (Fig. 2), while the lack of uptake is a sign of non-union (chronic disease) and decreased healing potential [17].

In patients with spondylolysis, a CT scan may show that everything is normal, a stress reaction, an acute stress fracture (early stage), progression of the condition, or terminal stage (chronic or pseudoarthrosis) [18,19]. It should be noted that stress reaction is the body's adaptive and reactive response to extraordinary, repeated stresses. In hyperlordosis posture, the inferior articular process of the superior vertebra applies a traction force on the pars interarticularis of the vertebra below and this part eventually fails anteriorly [20]. At first, this reaction results in microfracture of the cancellous bone associated with edema and hemorrhage. This bone bruising stage
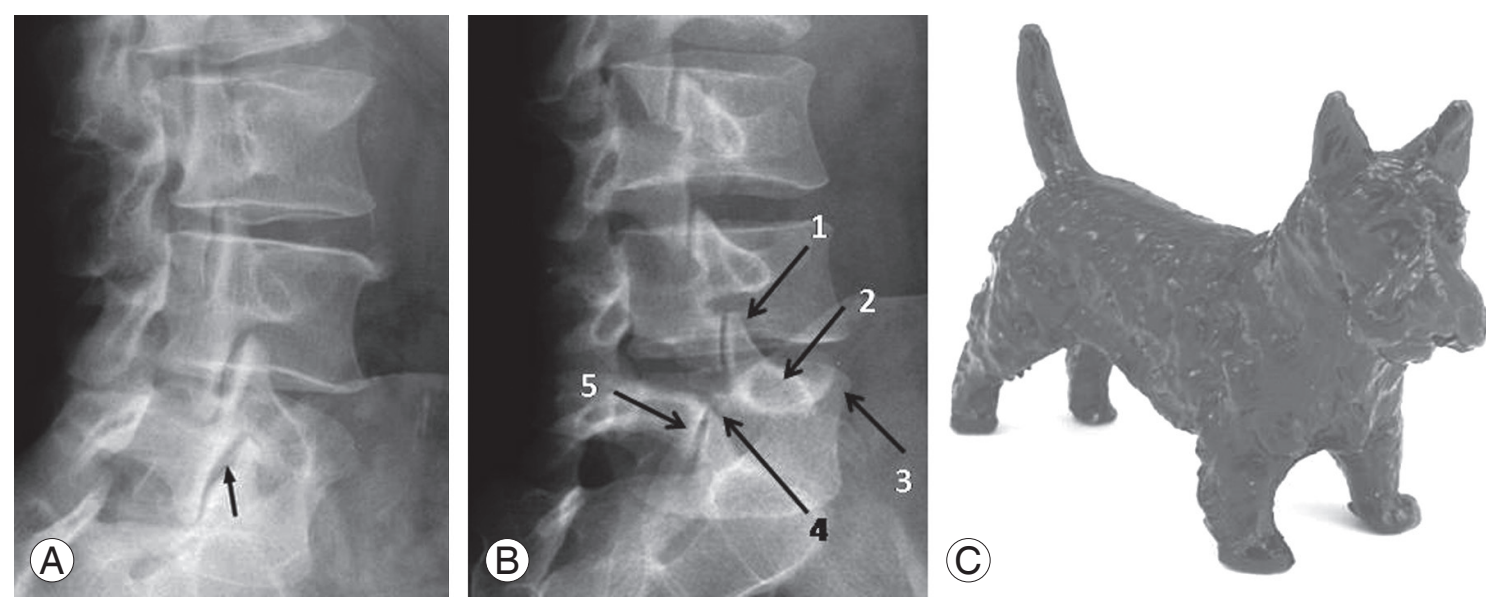

Fig. 1. (A, B) Oblique lumbosacral views of a normal and abnormal spine, respectively, for detection of a broken neck or a collar in the Scotty dog (C). The ear (1) is the superior articular process, the eye (2) is the pedicle, the nose (3) is the transverse process, the neck (4) is the pars interarticularis, and the frontal limb (5) is the inferior articular process. 
can be seen more clearly in an MRI while a CT scan may be interpreted as normal [21]. Acute lesions in an MRI show increased signal intensity on T2-weighted images that are indicative of bone marrow edema [21]. When the bony disruption progresses to the cortical bone, a CT scan becomes the most sensitive modality. Chronic stress reaction in CT is presented as increased sclerosis and thickening of trabeculae due to repeated fractures and healings [22]. An acute stress fracture (early stage) has a sharp margin of bone disruption and is defined as a fissure in the pars. In progressive stage, the defect is still narrow but has round edges, while in a chronic or terminal stage, a wide defect is observed with hazy, blunt and sclerotic margins.

It should not be forgotten that in chronic cases, every bony disruption observed in the posterior elements of a vertebra is not always indicative of spondylolysis. If the axial slice was taken at the level of intervertebral disc space, this is not a pseudoarthrosis of the spondylolysis. This is a degenerative joint disease of the facet articulations, because the typical location of pars defect in axial
CT scanning is inside the cuts taken at the pedicles of the involved vertebra.

\section{Treatment}

In those patient where no abnormality observed in radiographs, bone scan, and CT scan, spondylolysis is certainly ruled out. If a pre-lysis defect is observed in an MRI or CT scan associated with positive bone scan, the preferred treatment is avoidance of harmful activities that would create hyperlordosis and rotational spinal loading (like weight-lifting, diving, wrestling, rowing, and gymnastics) $[23,24]$. A brace and surgery are unnecessary.

In those spondylolytic patients with a negative bone scan, non-union of the pars is diagnosed and the recommended initial treatment is conservative and directed at improving clinical disabilities, not healing the pars defect. The pain usually resolves when harmful activities are stopped for 2 to 3 weeks, with aggressive rehabilitation, and analgesic consumption. After this period of time, the patient can gradually resume his/her physical activity


Fig. 2. A 13-year-old girl presented with acute low back pain after a sport accident. On plain radiographies (A) and (B) L4 spondylolysis is suspicious. Single photon emission computed tomography scanning (C) shows bilateral increased tracer uptake in the posterior neural arc of L4 vertebra (arrows). 
even in the championship.

Ultimately, in cases of acute spondylolysis (acute fracture in CT and hot spot in bone scan), the primary treatment is a lumbosacral orthosis in order to decrease lumbar lordosis, even by 15 of degrees flexion [25]. A brace regimen consists of wearing it full time ( $>20 \mathrm{hr} /$ day) for three months with no sports activities allowed. After that, another three months full-time bracing should be continued, but allowing sport activity. At the end of each phase, the patient should be seen to be evaluated for pain. If the pain persists, surgery is indicated [26]. Bracing for more than six months is not indicated and is useless [27].

It is known that more than $80 \%-90 \%$ of the patients with spondylolysis improve with non-surgical treatment $[26,28,29]$. The healing rates in acute unilateral, acute bilateral, and chronic lesions are 100\%, 50\%, and $0 \%$, respectively $[21,28]$. Stability of a fibrous union is acceptable, therefore, non-healed lesions are frequently asymptomatic throughout life and do not usually progress to spondylolisthesis, especially after skeletal maturity achieved [30].

In growing children with lumbar spondylolysis, repeated clinical examinations every six months are recommended until skeletal maturity is reached in order to detect the possible progression of vertebral slippage, but radiographs are usually reserved for those patients with associated pain or change in clinical posture, although progression to slip is not always associated with pain $[31,32]$. Because there is not a remarkable relationship between presence of spondylolysis on an X-ray and LBP, careful attention to the proper surgical indications is necessary. These include refractory LBP not related to other sources (it is preferred to prove the pars defect by direct injection of local anesthetic drugs preoperatively and under fluoroscopic control), progressive neurological deficit, and pain or disability that is incompatible with activity of daily living without any associated significant underlying psychological disorders $[3,8,22,33,34]$. We summarized this as an algorithmic approach to the patient with lumbar spondylolysis (Fig. 3).

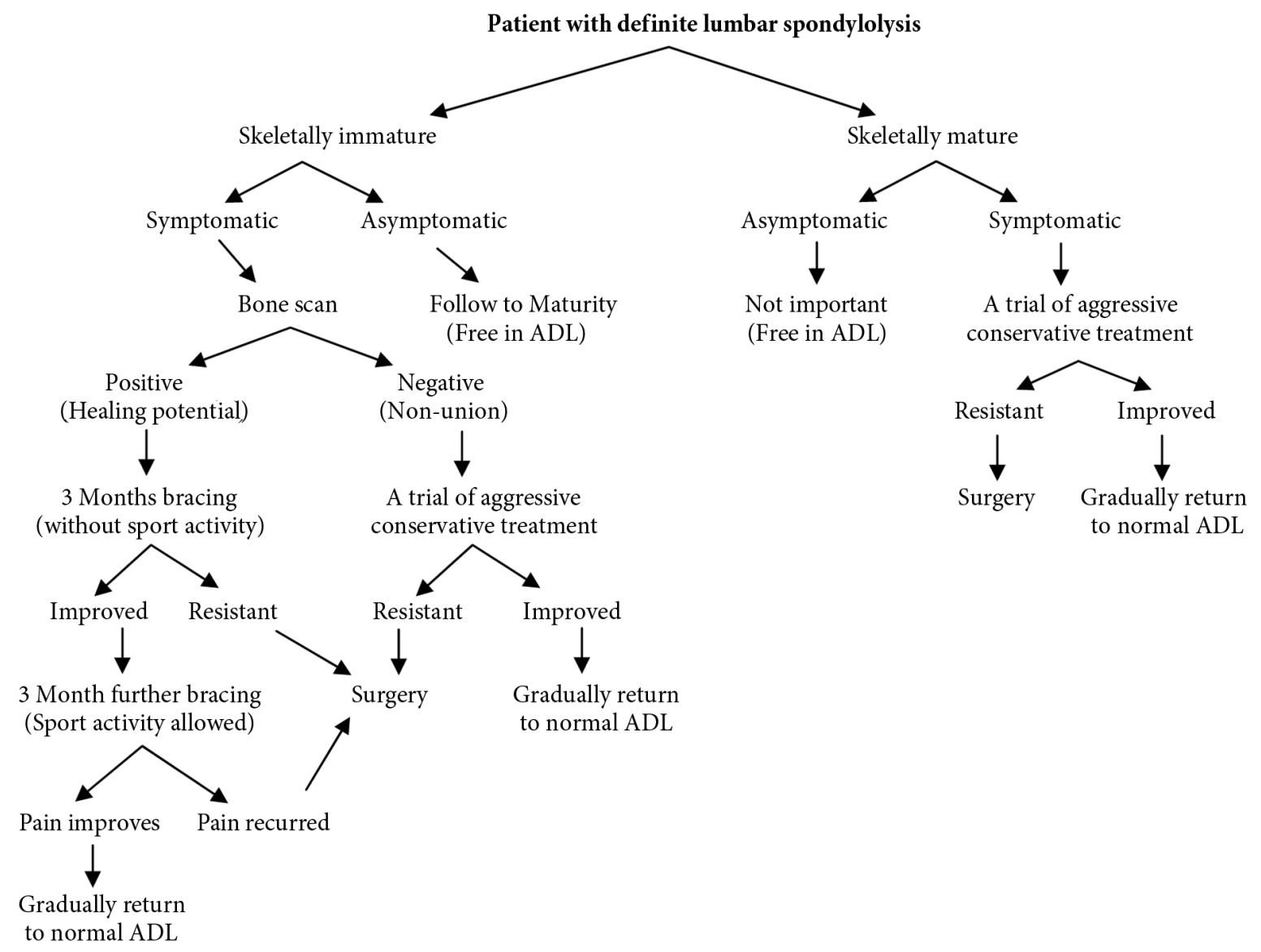

Fig. 3. An algorithmic approach to a patient with lumbar spondylolysis. ADL, activity of daily living. 


\section{Spondylolisthesis}

Usually Meyerding's grading system is used to describe the percentage of displacement of the inferior aspect of the superior slipped vertebra in relation to the superior border of the inferior vertebra [35]. Lumbar spondylolisthesis irrelevant to its specific underlying etiology should be appropriately diagnosed first. To obtain the proper diagnosis, standing anteroposterior and lateral X-rays of the lumbosacral area are needed, because in standing versus supine posture, the amount of vertebral slippage increases to $26 \%$ [36]. Therefore, there are many patients with lumbar spondylolisthesis who may not be diagnosed with supine MRI scanning (Fig. 4).

Appropriate treatment of spondylolisthesis is primarily dependent on the age of the patient. In skeletally immature patients with spondylolisthesis, if the amount of slippage is less than $50 \%$, the first line of treatment is conservative, regular following-up clinically and radiographically every 6-12 months until skeletal maturity in order to detect any progression of slippage. Usually vertebral slippage does not progress after this time. In the patients with a higher slip percentage and high dysplastic spondylolisthesis (significant lumbosacral kyphosis,

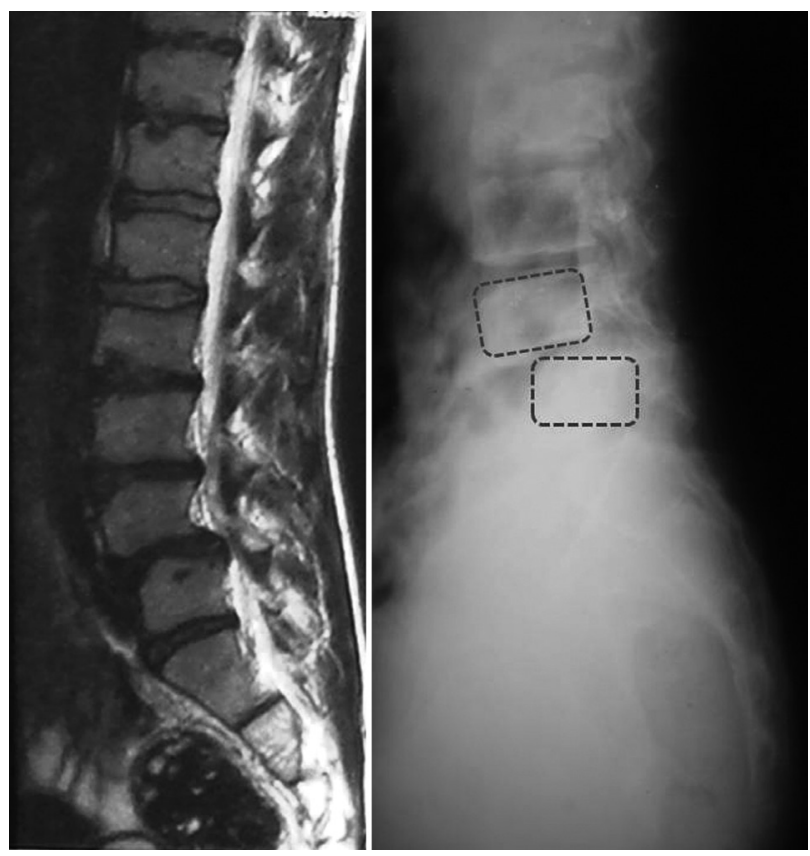

Fig. 4. A 17-year-old adolescent with L4-5 spondylolisthesis. Note the difference between the amount of slippage in the supine magnetic resonance imaging compared to the standing lateral view of the lumbosacral area (20\% vs. $40 \%$ ). a trapezoidal L5 associated with hypoplastic transverse processes, and sacral doming with a vertical sacrum), the probability of slip progression is higher and a shorter interval between follow-up visits is needed [37].

Surgery is indicated in less than $50 \%$ of pediatric patients with slippage who experience refractory symptoms (back pain, awkward gait, hamstring stiffness, or poor posture) after more than six months of conservative management, neurologic deficit, especially if they are deteriorating, an undesirable appearance and an increase in vertebral slippage $[8,27]$. In any immature patient with more than 50\% vertebral slippage regardless the clinical signs and symptoms, surgical intervention is necessary because the slippage is progressive and needs stabilization [27].

Surgical indications i $\mathrm{n}$ adult patients with lumbar spondylolisthesis have nothing to do with the severity or type of the vertebral slippage, but are completely dependent upon symptoms. One exception to this fact is pathologic spondylolisthesis, which requires a specific approach depending upon the underlying disorder (tumor, osteogenesis imprefecta, etc.). In cases with totally displaced vertebra (spondyloptosis), the primary treatment is non-surgical modalities. In the absence of sphincter complaints and cauda equina syndrome, the surgical outcome of early and late treatment in these patients are usually similar. Therefore, a trial period of three to six months of aggressive conservative treatment comprising physiotherapy, hydrotherapy, and analgesia are indicated. Patients who present with long-term intractable pain and complain that their condition interferes with their daily living activities or even persisting while at rest are usually treated surgically. Some researchers also emphasize performing dynamic flexion-extension views in symptomatic patients with spondylolysis and spondylolisthesis and believe those patients with more than $3 \mathrm{~mm}$ sagittal instability or $6^{\circ}$ a ngular instability should have surgery [38]. In Fig. 5, we presented an algorithmic approach in determining which patients should be treated surgically.

There are so many operating techniques and strategies for treatment of the patients with lumbar spondylolysis and spondylolisthesis that are beyond the scope of this paper and, therefore, we have not mentioned them.

\section{Conclusions}

Currently in the treatment of lumbar spondylosis and 




Fig. 5. An algorithmic approach to a patient with lumbar spondylolisthesis. ADL, activity of daily living.

spondylolisthesis, a lot of much attention has been paid to the surgical techniques and instrumentation used, especially in minimally invasive spinal surgeries, while basic concepts are sometimes ignored. The presence of an innocent lumbar spondylolisthesis on imaging studies should not cause the physicians to push the patient to have surgery. Careful attention to the proper indications can lead to appropriate treatment of this condition.

\section{Conflict of Interest}

No potential conflict of interest relevant to this article was reported.

\section{References}

1. Micheli LJ, Wood R. Back pain in young athletes. Significant differences from adults in causes and patterns. Arch Pediatr Adolesc Med 1995;149:15-8.

2. El Rassi G, Takemitsu M, Woratanarat P, Shah SA. Lumbar spondylolysis in pediatric and adolescent soccer players. Am J Sports Med 2005;33:1688-93.

3. Kalichman L, Kim DH, Li L, Guermazi A, Berkin V, Hunter DJ. Spondylolysis and spondylolisthesis: prevalence and association with low back pain in the adult community-based population. Spine (Phila $\mathrm{Pa}$ 1976) 2009;34:199-205.

4. Sairyo K, Katoh S, Sasa T, et al. Athletes with unilateral spondylolysis are at risk of stress fracture at the contralateral pedicle and pars interarticularis: a clinical and biomechanical study. Am J Sports Med 2005;33:583-90.

5. Beutler WJ, Fredrickson BE, Murtland A, Sweeney CA, Grant WD, Baker D. The natural history of spondylolysis and spondylolisthesis: 45-year followup evaluation. Spine (Phila Pa 1976) 2003;28:102735.

6. Roche MB, Rowe GG. The incidence of separate neural arch and coincident bone variations; a survey of 4,200 skeletons. Anat Rec 1951;109:233-52.

7. Frennered AK, Danielson BI, Nachemson AL, Nordwall AB. Midterm follow-up of young patients fused in situ for spondylolisthesis. Spine (Phila Pa 1976) 1991;16:409-16.

8. Tsirikos AI, Garrido EG. Spondylolysis and spondylolisthesis in children and adolescents. J Bone Joint Surg Br 2010;92:751-9.

9. Lonstein JE. Spondylolisthesis in children. Cause, 
natural history, and management. Spine (Phila Pa 1976) 1999;24:2640-8.

10. Beck NA, Miller R, Baldwin K, et al. Do oblique views add value in the diagnosis of spondylolysis in adolescents? J Bone Joint Surg Am 2013;95:e65.

11. Standaert CJ, Herring SA. Spondylolysis: a critical review. Br J Sports Med 2000;34:415-22.

12. Standaert CJ, Herring SA. Expert opinion and controversies in sports and musculoskeletal medicine: the diagnosis and treatment of spondylolysis in adolescent athletes. Arch Phys Med Rehabil 2007;88:53740.

13. Read MT. Single photon emission computed tomography (SPECT) scanning for adolescent back pain. A sine qua non? Br J Sports Med 1994;28:56-7.

14. Motley G, Nyland J, Jacobs J, Caborn DN. The pars interarticularis stress reaction, spondylolysis, and spondylolisthesis progression. J Athl Train 1998;33:351-8.

15. Sakai T, Sairyo K, Mima S, Yasui N. Significance of magnetic resonance imaging signal change in the pedicle in the management of pediatric lumbar spondylolysis. Spine (Phila Pa 1976) 2010;35:E641-5.

16. Sairyo K, Sakai T, Yasui N. Conservative treatment of lumbar spondylolysis in childhood and adolescence: the radiological signs which predict healing. J Bone Joint Surg Br 2009;91:206-9.

17. van den Oever M, Merrick MV, Scott JH. Bone scintigraphy in symptomatic spondylolysis. J Bone Joint Surg Br 1987;69:453-6.

18. Gregory PL, Batt ME, Kerslake RW, Scammell BE, Webb JF. The value of combining single photon emission computerised tomography and computerised tomography in the investigation of spondylolysis. Eur Spine J 2004;13:503-9.

19. Fujii K, Katoh S, Sairyo K, Ikata T, Yasui N. Union of defects in the pars interarticularis of the lumbar spine in children and adolescents. The radiological outcome after conservative treatment. J Bone Joint Surg Br 2004;86:225-31.

20. Terai T, Sairyo K, Goel VK, et al. Spondylolysis originates in the ventral aspect of the pars interarticularis: a clinical and biomechanical study. J Bone Joint Surg Br 2010;92:1123-7.

21. Sairyo K, Katoh S, Takata Y, et al. MRI signal changes of the pedicle as an indicator for early diagnosis of spondylolysis in children and adolescents: a clini- cal and biomechanical study. Spine (Phila Pa 1976) 2006;31:206-11.

22. Millson HB, Gray J, Stretch RA, Lambert MI. Dissociation between back pain and bone stress reaction as measured by CT scan in young cricket fast bowlers. Br J Sports Med 2004;38:586-91.

23. Soler T, Calderon C. The prevalence of spondylolysis in the Spanish elite athlete. Am J Sports Med 2000;28:57-62.

24. Rossi F, Dragoni S. Lumbar spondylolysis: occurrence in competitive athletes. Updated achievements in a series of 390 cases. J Sports Med Phys Fitness 1990;30:450-2.

25. Blanda J, Bethem D, Moats W, Lew M. Defects of pars interarticularis in athletes: a protocol for nonoperative treatment. J Spinal Disord 1993;6:406-11.

26. Steiner ME, Micheli LJ. Treatment of symptomatic spondylolysis and spondylolisthesis with the modified Boston brace. Spine (Phila Pa 1976) 1985;10:93743.

27. Herman MJ, Pizzutillo PD, Cavalier R. Spondylolysis and spondylolisthesis in the child and adolescent athlete. Orthop Clin North Am 2003;34:461-7.

28. Sys J, Michielsen J, Bracke P, Martens M, Verstreken J. Nonoperative treatment of active spondylolysis in elite athletes with normal X-ray findings: literature review and results of conservative treatment. Eur Spine J 2001;10:498-504.

29. Kurd MF, Patel D, Norton R, Picetti G, Friel B, Vaccaro AR. Nonoperative treatment of symptomatic spondylolysis. J Spinal Disord Tech 2007;20:560-4.

30. Hu SS, Tribus CB, Diab M, Ghanayem AJ. Spondylolisthesis and spondylolysis. J Bone Joint Surg Am 2008;90:656-71.

31. Seitsalo S, Osterman K, Hyvarinen H, Tallroth K, Schlenzka D, Poussa M. Progression of spondylolisthesis in children and adolescents. A long-term follow-up of 272 patients. Spine (Phila Pa 1976) 1991;16:417-21.

32. Fredrickson BE, Baker D, McHolick WJ, Yuan HA, Lubicky JP. The natural history of spondylolysis and spondylolisthesis. J Bone Joint Surg Am 1984;66:699707.

33. Sutton JH, Guin PD, Theiss SM. Acute lumbar spondylolysis in intercollegiate athletes. J Spinal Disord Tech 2012;25:422-5.

34. Peer KS, Fascione JM. Spondylolysis: a review and 
treatment approach. Orthop Nurs 2007;26:104-11.

35. Meyerding HW. Low backache and sciatic pain associated with spondylolisthesis and protruded intervertebral disc: incidence, significance, and treatment. J Bone Joint Surg Am 1941;23:461-70.

36. Warner WC, Sawyer JR, Kelly DM. Scoliosis and kyphosis. In: Campbell WC, Canale ST, Beaty JH, editors. Campbell's operative orthopaedics. Philadelphia, PA: Elsevier/Mosby; 2013. p.1838-56.
37. Marchetti PC, Bartolozzi P. Classification of spondylolisthesis as a guideline for treatment. In: Bridwell $\mathrm{KH}$, deWald RL, editors. The textbook of spinal surgery. 2nd ed. Philadelphia: Lippincott; 2005.

38. Niggemann P, Kuchta J, Beyer HK, Grosskurth D, Schulze T, Delank KS. Spondylolysis and spondylolisthesis: prevalence of different forms of instability and clinical implications. Spine (Phila Pa 1976) 2011;36:E1463-8. 